\title{
Impact of Aggregation Methods on Countries' Ranking in Composite Index of National Competitiveness
}

\author{
Marta Nečadováa \\ University of Economics, Prague
}

\begin{abstract}
The Global Competitiveness Index (GCI), the composite indicator of national competitiveness discussed in this paper, is widely accepted by policymakers and other authorities for its ability to integrate a significant amount of relevant information about competitive advantages and disadvantages of countries on different levels of development. The explanatory power of this international ranking depends strongly on the choices made during the process of construction of the composite index $(\mathrm{Cl})$. Being inspired by the newly proposed WEF's attitude (the methodology of the $\mathrm{GCl}$ 4.0 based on the same weights for the pillars) we used the arithmetic and geometric mean on different levels of aggregation - on the level of the twelve pillars and the level of the three sub-indices (basic requirements, efficiency enhancers, innovation and sophisticated factors). This attitude enables us to reduce the methodological problem of compensability among the pillars and sub-indices. This paper explains the differences caused by the abovementioned methodological changes. Our analysis is concentrated on changes in the competitive position of three Asian countries Vietnam, South Korea and Japan - caused by using different aggregation methods.
\end{abstract}

Keywords: Aggregation methods, composite indicator, Global Competitiveness Index, Global Competitiveness Report, national competitiveness

JEL classification: E60, F40, F60

\section{Introduction}

The aim of the $\mathrm{GCl}$ - a well-known composite indicator of national competitiveness - is to provide a comprehensive view on national competitiveness, a phenomenon, which cannot be captured by one single indicator without any doubts. The explanatory power of a composite indicator is influenced by the methodology of its construction. The building of a composite indicator is based on several necessary steps: development of a theoretical framework, identification and development of suitable variables, standardisation of variables, weighting variables individually and in groups, and finally conducting sensitivity tests on the robustness of aggregated variables. From the three latest GCR editions (the Global Competitiveness Report published by World Economic Forum), it is clear that changes in international economic relations after the world

\footnotetext{
University of Economics, Prague, W. Churchill Sq. 1938/4, 13067 Prague 3 - Žižkov, Czech Republic. Email: necadova@vse.cz

Acknowledgement: This article is provided as one of the outputs of the research project of the Faculty of Business Administration IP 300040 "Competitiveness".
} 
financial crisis and modifications of economic relations among countries connected with globalisation were taken into account as well. The group of WEF's authors comes with some significant modifications to the original methodology and offers a refurbished attitude to the evaluation of international competitiveness. The key change resides in a different attitude to the final aggregation. While the original methodology was based on the differentiation of countries according to the stage of development, the new methodology propounds the same weighting system for all countries. This modified WEF's approach inspires us to use the freely accessible WEF data, apply different aggregation methods and evaluate their impact on the ranking of three Asian economies - Japan, South Korea and Vietnam. Our choice of this sample countries is determined by our primary goal - to show the impact of alternative attitudes to the final aggregation on the ranking of big countries in different stages of development (Japan and South Korea vs Vietnam) with different macroeconomic problems, different competitive advantages, and differently balanced values among pillars and sub-indices.

The analysis of this paper is concentrated on changes in the competitive position of three Asian countries, namely Vietnam, South Korea and Japan. Japan is a developed country with a ranking in the top 10 . The ranking is positively evaluated by excellent results in the innovation and sophistication factors. However, the macroeconomic environment continues to undermine Japan's competitiveness performance. With the exception of this aspect of Japanese competitiveness, the results in other pillars are relatively balanced. Therefore, it is interesting to test the impact of different aggregation methods on the Japanese rank. Compared to other developed economies, South Korea presents significant disparities between pillars and a deteriorating trend in the overall rank with signs of stabilisation at the end of the reference period (WEF's data from the GCR 2007-17). Vietnam is a developing country with an improving trend in competitiveness. Its ranking in the last edition of the GCR is ten places better than in the first edition, i.e. the GCR 2007-8, with different weights of pillars and sub-indices in the original WEF methodology.

\section{Theoretical Framework}

\subsection{The Original WEF Methodology - the Pillars of Competitiveness and Stages of Development}

The Global Competitiveness Report (GCR) is published annually by the World Economic Forum (WEF). This annual report is based mostly on soft data. This attitude allows the GCR's publishers to follow and evaluate a bigger number of countries on different levels of development than the World Competitiveness Yearbook (published by the IMD), the second most prestigious international competitiveness ranking. In the GCR 201718 (the last issue of the report where the methodology is based on different stages of development - this is the original methodology in our paper - were used), 137 countries were evaluated using 114 qualitative and quantitative indicators describing the macroeconomic and microeconomic factors of competitive advantage. Indicators derived from the survey were always expressed as scores on a 1 to 7 scale, with 7 being the most desirable outcome. To make aggregation possible, the hard variables were 
converted to a 1 to 7 scale to align them with the Executive Opinion Survey (the EOS) results. The WEF used the min-max transformation (distance from the best and worst performers). The weighting approach of the WEF proceeded in two stages.

Firstly, the underlying indicators were organised into thematic subgroups. The same weights were assigned to the variables within the same subgroups (the WEF used the arithmetic mean to aggregate individual indicators within a category); different weights for the subgroups should indicate the different importance for the vital pillar. Secondly, the pillars within the sub-index had the same weight. Thirdly, the sub-indices were weighted to build a composite indicator $(\mathrm{Cl})$. The weight put on each of the three subindices (basic requirements, efficiency enhancers, and innovation and sophistication factors) depended on the stage of development of each country. For countries in transition between stages, the weighting applied to each sub-index changed according to the country's results. Countries which were in between two of the three major stages were allotted a set of weights, which gradually changed as the country moved to the more advanced stage. According to WEF (2010), this attitude reproduces the smooth transition from a lower stage of development to the higher level, implying that countries possessing the economic capacity to perform better - reflected by their weight values - are expected to score higher in the different dimensions of the $\mathrm{GCl}$. Concerning ranking, most of the countries would gain positions if assigned the weights of the next lower development stage and would lose positions if assigned the weights of the next higher development stage (WEF, 2010).

The Global Competitiveness Index (GCl) of a country was computed in the following way:

$$
\mathrm{GCl}_{i j}=w j 1 \bullet \text { BASIC }_{i}+w j 2 \bullet \text { EFFICIENCY }_{i}+\left(1-w j 1-w_{j 2}\right) \bullet \text { INNOVATION }_{i}
$$

for country $i$ and its stage of economic development $j$, where BASIC, EFFICIENCY and INNOVATION are sub-indices explained in Table 1 , and wj1 are wj2 are weights of subindices. Since our primary goal is to show the differences in countries' ranking caused by the different methods of aggregation, a more detailed view of WEF's weighting system is necessary. As an example, Hudrlikova (2013) pointed out that deconstructing the $\mathrm{Cl}$ is useful for the correct understanding and interpretation of the $\mathrm{Cl}$ results.

Table 1 shows the different weights for pillars and variables depending on the stage of development. Due to our choice of countries and their different stages of development (Japan and South Korea are in the 3rd stage, Vietnam is between the 1st and 2nd stage), it is necessary to provide the following view on the WEF's weighting scheme for better understanding of the changes in country ranking when we are going to use the different weighting scheme.

The original methodology admitted the differences in weights by pillar and country, from 5 to 15\%, according to (1) the sub-index to which the pillar belongs and (2) the country's stage of development. In the original methodology, the basic requirements (i.e., institutions, infrastructure, macroeconomic environment, and health and primary education) account for $65 \%$ of the overall $\mathrm{GCl}$ score in the case of low-income countries (i.e., those with GDP per capita of less than US\$2,000) and commodity-dependent economies (i.e., those whose share of minerals in exports exceeds $70 \%$ ), while innovation and sophistication factors obtained a weight of $5 \%$. Our detailed view of 
Table 1. The present WEF's weighting scheme (the $\mathrm{GCl}$ )

\begin{tabular}{|c|c|c|c|c|}
\hline WEF sub-indices ${ }^{a}$ & WEF pillars ${ }^{b}$ & $\begin{array}{c}\text { Stage } 3 \\
(20: 50: 30) \\
A: B: C\end{array}$ & $\begin{array}{c}\text { Stage } 2 \\
(40: 50: 10) \\
A: B: C\end{array}$ & $\begin{array}{c}\text { Stage } 1 \\
(60: 35: 5) \\
A: B: C\end{array}$ \\
\hline \multirow{5}{*}{$\begin{array}{l}\text { A. Basic } \\
\text { requirements } \\
(16 / 37)\end{array}$} & 1. Institutions $(0 / 21)^{*}$ & 5 & 10 & 15 \\
\hline & 2. Infrastructure $(3 / 6)^{*}$ & 5 & 10 & 15 \\
\hline & 3. Macroeconomic environment $(5 / 0)$ & 5 & 10 & 15 \\
\hline & 4. Health and primary education $(6 / 4)$ & 5 & 10 & 15 \\
\hline & 5. Higher education and training $(2 / 6)$ & 8.5 & 8.5 & 5.95 \\
\hline \multirow{5}{*}{$\begin{array}{l}\text { B. Efficiency } \\
\text { enhancers } \\
(13 / 36)\end{array}$} & 6. Goods market efficiency $(5 / 11)$ & 8.5 & 8.5 & 5.95 \\
\hline & 7. Labour market efficiency $(2 / 8)^{*}$ & 8.5 & 8.5 & 5.95 \\
\hline & 8. Financial market development $(0 / 8)$ & 8.5 & 8.5 & 5.95 \\
\hline & 9. Technological readiness $(4 / 3)^{*}$ & 8.5 & 8.5 & 5.95 \\
\hline & 10. Market size $(2 / 0)$ & 8.5 & 8.5 & 5.95 \\
\hline \multirow{2}{*}{$\begin{array}{l}\text { C. Innovation and } \\
\text { sophistication factors } \\
(1 / 17)\end{array}$} & 11. Business sophistication $(0 / 10)^{*}$ & 15 & 5 & 2.5 \\
\hline & 12. Innovation $(1 / 7)^{*}$ & 15 & 5 & 2.5 \\
\hline
\end{tabular}

Note: ${ }^{a, b}$ The quantities of two types of variables used in sub-indices and pillars (hard data/soft data) are listed in the 1st and 2nd column (in brackets). Weights of sub-indices for the different stages of development are mentioned in the headlines of the $3 \mathrm{rd}, 4$ th, and 5 th column (in brackets). The content of the table comprises weights of pillars. Pillars with "*" sign contain indicators which enter into the $\mathrm{GCl}$ in two different pillars. Avoiding double counting is assured by giving a half-weight to this variable.

Source: WEF (2017b), author's processing.

the WEF methodology allows us to identify the pillars with high expected influence on the final ranking for Japan and South Korea (11th pillar: business sophistication and the 12th pillar: innovation), and for Vietnam (the pillar of basic requirements). From our point of view, the above-described weighting system can explain the better position of the developing countries in the WEF ranking compared to the results of our $\mathrm{GCl}$ modifications described in the analytical part of this paper.

\subsection{The New WEF Methodology - GCl 4.0}

Permanent changes in economic reality, challenges connected with the Fourth Industrial Revolution (4IR), new empirical evidence and new data were the fundamental reasons for the WEF's consideration about changes in the methodology of international ranking. The goal is to ensure that the index remains a relevant source of information for multistakeholder dialogue and policymakers in the years to come (WEF, 2017b).

The pillars (see Table 2) are organised into four components: enabling environment, human capital, markets and innovation ecosystem. These four components are used only for presentation and analysis purposes; they do not affect the calculation of the index. The 12 pillar scores are averaged to produce the overall $\mathrm{GCl}$ score, with each pillar weighted equally (8.33\%). The $\mathrm{GCl} 4.0$ comprises 99 indicators (compared with 114 in the original methodology). The extent of the changes is significant compared 
Table 2. The new WEF methodology (the $\mathrm{GCl} 4.0$ )

\begin{tabular}{llll}
\hline Sub-indices & Pillars (hard data/soft data) & Sub-indices & Pillars (hard data/soft data) \\
Enabling & 1. Institutions (2/18) & Markets & 7. Product market $(2 / 6)$ \\
Environment & 2. Infrastructure (7/5) & & 8. Labour market (3/9) \\
& 3. ICT adoption (5/0) & & 9. Financial system (6/3) \\
4. Macroeconomic stability (3/0) & & 10. Market size (2/0) \\
Human & 5. Health (1/0) & Innovation & 11. Business dynamism (4/4) \\
Capital & 6. Skills $(3 / 6)$ & Ecosystem & 12. Innovation capacity (6/4) \\
\hline
\end{tabular}

Note: All pillars are weighted equally (8.33\%).

Source: WEF (2019b), author's processing.

to the original methodology: $67 \%$ of the indicators are new. The number of indicators derived from the Executive Opinion Survey (EOS) was reduced from 80 to 44 and their combined weight accounts for $30 \%$ of the overall score, down from between $69 \%$ (for advanced economies) and 57\% (for least-developed economies) in the $\mathrm{GCl}$.

Comparison of Table 1 and Table 2 shows that the discontinuation of stages of development significantly alters the weighting scheme used to compute the overall $\mathrm{GCl}$ score. The 12 pillars in the $\mathrm{GCl} 4.0$ are weighted equally, each contributing $8.33 \%$. The new scheme benefits those low-income and commodity-dependent countries that perform better in the innovation ecosystem. However, it penalises countries which have been neglecting some critical enablers of competitiveness, e.g. ICT adoption, skills of workforce, development of financial system, product and labour market (WEF, 2017b). This change reflects the latest thinking that many paths to growth are possible and better reflects the aspirations of low-income and commodity-exporting countries. Within each pillar, changes in the form of addition, deletion, modification, and reshuffling of concepts and individual indicators have a significant impact on the performance of a country (a concept is a well-defined driver of competitiveness that is assessed through one or more individual indicators). The direction and magnitude of this impact depend on: (1) the country's performance in the concept/indicator that has been added/deleted/modified, and (2) the change in the implicit weight of the various components of the pillar (WEF, 2017b). In the new methodology, recent empirical evidence has led to the introduction of new concepts; for example, the institutions pillar features two new concepts - checks and balances and social capital - both assessed through new indicators and existing ones that were moved to these categories. In another example, the skills pillar which in the original methodology looked only at the education of the future workforce, now includes an assessment of the skills and educational attainment of the current workforce. This concept is composed of new indicators exclusively (WEF, 2017b).

As the creators of the $\mathrm{GCl} 4.0$ observed, each of the changes to the original methodology has an impact - positive or negative - on how a country is thriving in a concept, pillar, or the overall $\mathrm{GCl}$. However, the overall impact is difficult to isolate and therefore to quantify due to the many overlapping and interconnected changes (WEF, 2017b). 


\section{Literature Review}

As Freudenberg (2003) and others remarked, composite indices (Cl) have a lot of methodological difficulties which "must be confronted... and the $\mathrm{Cl}$ can be easily manipulated to produce desired outcomes" (Freudenberg, 2003, p. 5). The methodological manual of the European Commission (OECD, 2008) deals with in depth the main pros and cons of using composite indicators and gives a detailed description of all steps necessary for construction of the $\mathrm{Cl}$.

Saisana, Saltelli and Tarantola (2005) turned their attention to the following three types of uncertainties in building composite indicators: a) alternative normalisation methods for values of the indicators, b) alternative weighting approaches, and c) uncertainty in the weights of the sub-indicators. These authors proposed to use the uncertainty and sensitivity analysis to gain useful insights during the process of building composite indicators. Berger and Bristow (2009), Cho and Moon (2013), Ochel and Röhn (2006) and others argued that the most famous competitiveness reports (the Global Competitiveness Report published by the WEF and the World Competitiveness Yearbook released by the IMD) do not have any strong theoretical background. According to Cho and Moon (2013), traditional competitiveness reports are unsatisfactory in many respects. The absence of a strong theoretical background is regarded as the fundamental problem - the reports lack a rigorous theoretical explanation. Therefore, it is unclear why some factors are essential and others are not - and the probable cause of the frequent changes of the evaluation models. Critics of WEF's and IMD's attitude emphasise that the lack of a rigorous theory is the main reason for the frequent changes in the methodology of the abovementioned international rankings.

The second main critical argument is connected to the impact of subjectivity and lower explanatory power of soft data. Advantages and disadvantages of using soft data had been summarised, e.g. in Necadova (2015), and Necadova and Soukup (2013).

Ochel and Röhn (2006) perceived the importance of national specifics for the explanatory power of survey data and argued that cross-country analysis cannot account for specific characteristics of individual countries (e.g. national sentiment). The economic and culture distance among countries can cause the so-called national bias (Browne, Di Battista, Geiger, \& Verin, 2016), which enters into respondents' answers in the Executive Opinion Survey (EOS) and can cause a discrepancy between real economic performance and respondents' sentiment. As an example, Necadova (2019) showed that worse European results in competitiveness indicators based on soft data (compared to the developing world's regions) are determined by differences in cultural and national sentiment, particularly by the more negative sentiment in developed countries, especially in the post-crisis period. It is clear that the original WEF methodology (representation of soft data in WEF's dataset) and weighting scheme can support this type of distortion.

Using soft data is connected with another methodological problem - doublecounting the same behaviour or aspects (e.g., Berger \& Bristow, 2009; Freudenberg, 2003; Ochel \& Röhn, 2006). The weights should ideally be based on an underlying theoretical framework. As Freudenberg (2003) and others mention, when the importance of 
variables or sub-indices is not clearly defined, equal weights are usually applied. Users of this composite index should take into account that the identical weighting approach comes with the risk that some performance aspects will be double weighted. This methodological problem stems from the similarity among some variables (two or more indicators measure the same or very similar behaviour). Therefore, the respondent does not perceive the difference between variables and chooses the same evaluation.

The compensability of indicators, pillars and sub-indices constitutes another often criticised aspect (e.g., Ochel \& Röhn, 2006; Perez-Moreno, Rodríguez, \& Luque, 2016). Equal weighting within subgroups of variables and linear aggregation of subindices allow total substitutability among variables and pillars. To eliminate these methodological problems, the robust econometric analysis on all levels of aggregation is recommended. Freudenberg (2003) advised using the bivariate correlation of selected variables - both within a sub-component and in the overall dataset.

The aim of the robustness analysis (WEF, 2010) which was realised by the Joint Research Centre was to assess the extent to which all necessary choices connected with the construction of the composite indicator (some of them considered crucial) might affect the final score and ranking of the index. Result of the robustness analysis initiated by the WEF was that the width of error bars tends to decrease as the development stage increases. This finding insinuates that countries in the first development stage are more affected by the compensability among indicators within each pillar group. On the contrary, the highest-ranked countries, with only a few exceptions, are the least affected by compensability, meaning that the best performers have high scores in almost every aspect of competitiveness.

\section{Methodology and Aims of Analysis}

Our methodological attitude to WEF's data processing was inspired by the new WEF methodology (the $\mathrm{GCl}$ 4.0). The essential methodological change (the same weighting scheme for all countries) reflects the latest thinking that many paths to growth are possible (WEF, 2017b). This methodology is, therefore, less prescriptive about the path of development and does not distinguish among stages of development. According to WEF (2017b), their new attitude to the $\mathrm{Cl}$ construction enables a better reflection of the aspirations of low-income and commodity-exporting countries.

With the aim to eliminate the impact of different weighting systems on the overall ranking, we constructed two forms of "adjusted GCl". The AGCI12 is calculated as a linear aggregation of 12 pillars; the $\mathrm{AGCl} 3$ is the linear aggregation of 3 sub-indices (arithmetic mean used as an aggregation method). A disadvantage of the linear aggregation method is the substitutability (compensability) among pillars (a lower value of one pillar can be compensated by a higher value in the other pillars). The AGCI3 is fairer than the original WEF methodology since the same weight is given to all subindices and the innovative pillars (the 11th pillar and the 12th pillar) are considered to be the key pillars for a sustainable competitive advantage. The AGCI12 partly eliminates differences among weights of pillars and therefore reduces compensability among pillars from the sub-index $A$ (basic requirements) on the one hand and pillars from sub-indices $B$ (efficiency enhancers) and C (innovative and sophisticated factors) on the other hand. 
This type of substitution is typical for developing countries because improvements in indicators for these group of countries are usually connected with the pillars of subindex A. Due to the original WEF's weighting scheme (higher weights of the pillars which evaluate the basic requirements for global competitiveness), developing countries usually gained an advantage - the better final value of the $\mathrm{GCl}$. The GAGCI12 and the GAGCI3 are computed as the geometric mean of pillars (the GAGCI12) or sub-indices (the GAGCI3) and therefore can decrease a methodological problem with substitutability (compensability) among the pillars (sub-indices). The lower difference between AGCI and $\mathrm{GAGCl}$ indicates more equal values across pillars (sub-indices). Geometric mean rewards the countries with more balanced competitiveness indicators on the level of pillars (GAGCI12) and the level of sub-indices (GAGCl3).

The first aim of our analysis is to explain the changes in countries' competitiveness during the reference period which is given by the time series in WEF's dataset (20072017) and compare our results ( $\mathrm{AGCl} 12, \mathrm{AGCl} 3$, GAGCI12 and $\mathrm{GAGCl}$ ) with the $\mathrm{GCl}$. Our explanation of the differences in countries' ranking is grounded in the following assumptions: 1) the different weights of pillars and sub-indices, 2) the countries' predisposition to compensability among sub-indices and pillars, and 3) the disposition of pillars to improve or deteriorate the final ranking. The variability (measured by the standard deviation) of pillars' results for every country and the variability of countries' results in the particular pillars were used as a suitable tool for the evaluation of the abovementioned predispositions.

Due to changes in the number of evaluated countries during the reference period, we adjusted the WEF's data. All countries which were not evaluated in the first year in the WEF's Dataset (2007) were eliminated. Therefore, there are 114 countries in our sample.

The second aim is to identify the strengths and weaknesses of the competitiveness of Japan, South Korea and Vietnam in the period 2007-17 (in the GCR 200717). Identification of competitive pros and cons is very useful for an explanation of differences in countries' ranking according to suggested alternatives to the $\mathrm{GCl}$. The last aim is to compare the average countries' results in the GCR (2007-17) where original methodology with different stages of development was applied with the average countries' results in the GCl 4.0 (WEF's data from the GCR 2017-19 were used).

\section{Results and Discussions}

Tables 3, 4 and 5 constitute the necessary steps for analysing our resulting data. Table 4 compares our weighting system (the linear aggregation of pillars in the AGCI12 and the linear aggregation of sub-indices in the $A G C l 3$ ) with the original WEF's linear aggregation (based on the different stages of development).

We can summarise that the AGCl3 can improve the country's ranking if the competitive advantage leans on innovation pillars. If a competitive disadvantage of the developed country is found in the sub-index of basic requirement, both adjusted indices - the AGCl3 and the AGCI12 - harm the country's evaluation compared to the $\mathrm{GCl}$.

However, differences among the final methods of aggregation (i.e. differences among weighting systems of pillars and sub-indices) are not the only factors with 
Table 3. Comparison of our weighting scheme and the WEF's scheme

\begin{tabular}{lccccc}
\hline \multirow{2}{*}{$\begin{array}{l}\text { Sub-indices } \\
\text { (number of pillars) }\end{array}$} & AGCl3 & AGCl12 & GCI (Stage 3) & GCI (Stage 1) & GCI (Stage 1-2)* \\
\cline { 2 - 6 } & $8.33 / 33.3$ & 8.33 & $5 / 20$ & $15 / 60$ & $14.1 / 56.4$ \\
\hline Basic requirement (4) & $5.56 / 33.3$ & 8.33 & $8.5 / 50$ & $5.95 / 35$ & $6.26 / 37.7$ \\
Efficiency enhancers (6) & $16.67 / 33.3$ & 8.33 & $15 / 30$ & $2.5 / 5$ & $2.95 / 5.9$ \\
$\begin{array}{l}\text { Innovation and } \\
\text { sophistication factors (2) }\end{array}$ & & & & & \\
\hline
\end{tabular}

Note: * In the GCR 2007-14 editions, Vietnam pertained to a group of countries in the 1st stage of development and from the GCR 2015 onwards, it belonged to the transition stage with adjusted weights.

Source: Own computation based on the WEF methodology, WEF (2017b).

significant impact on the countries' final results and ranks. As noted above, the basic critical argument against using the linear aggregation leans on the impacts of compensability (among variables, pillars and sub-indices) on the final value of the composite indicator and the countries' ranking. Due to this fact, it is necessary to consider the country's predisposition to compensability on the level of pillars and subindices (see Table 4). The country with higher variability of results in pillars (sub-indices) has a bigger tendency to substitute between worse and better results.

Using the standard deviation of pillars' and sub-indices' values, Table 4 describes the predispositions to compensability among pillars and sub-indices. Since our aim is to analyse the changes in ranking of the three chosen countries, the average variability in the whole sample (114 countries) and the standard deviations for our three countries are mentioned.

Table 4. Predispositions to compensability among pillars and sub-indices (2007-2017)*

\begin{tabular}{|c|c|c|c|c|c|c|}
\hline \multirow[b]{2}{*}{ Country } & \multicolumn{3}{|r|}{ Pillars } & \multicolumn{3}{|c|}{ Sub-indices } \\
\hline & $\begin{array}{c}\text { s.d. } \\
\text { (mean) }\end{array}$ & Rank & $\begin{array}{l}\text { s.d. (from the highest } \\
\text { to the lowest) }\end{array}$ & $\begin{array}{c}\text { s.d. } \\
\text { (mean) }\end{array}$ & Rank & $\begin{array}{l}\text { s.d. (from the highest } \\
\text { to the lowest) }\end{array}$ \\
\hline 114 countries & 0.738 & & & 0.434 & & \\
\hline Japan & 0.670 & 35. & $\begin{array}{l}2015,2014,2012,2013, \\
2016,2017,2010,2011, \\
2009,2008,2007\end{array}$ & 0.206 & 11. & $\begin{array}{l}2011,2010,2009,2012, \\
2007,2008,2013,2014, \\
2015,2017,2016\end{array}$ \\
\hline South Korea & 0.764 & 72. & $\begin{array}{l}2015,2014,2017,2016, \\
2013,2011,2012,2010, \\
2009,2008,2007\end{array}$ & 0.396 & 54. & $\begin{array}{l}2017,2016,2015,2011, \\
2014,2013,2012,2010, \\
2008,2009,2007\end{array}$ \\
\hline Vietnam & 0.716 & 44. & $\begin{array}{l}2007,2014,2015,2012, \\
2013,2008,2011,2016, \\
2010,2017,2009\end{array}$ & 0.437 & 58. & $\begin{array}{l}2015,2014,2017,2016, \\
2011,2013,2012,2010, \\
2007,2008,2009\end{array}$ \\
\hline
\end{tabular}

Note: * In this table, average values of the GCR 2007-2017 (i.e. average values of standard deviations (s.d.) observed in individual years) are presented.

Source: Author's calculation and processing based on the WEF methodology, WEF (2017a, b). 
Table 4 shows that the most significant predisposition for compensability among pillars is typical for South Korea (the ranking gives the 72 nd position from the lowest to the highest standard deviation). This South Korean predisposition is given by aboveaverage variability among the pillars. High disposition for substitution among the subindices is typical for Vietnam (the ranking gives the 58th position from the lowest to the highest standard deviation). Comparison with an arithmetical mean of the whole sample enables to say that Vietnam evinces an average rate of compensability among the sub-indices. Since Japan and South Korea show more balanced results, it can be concluded that their predisposition for compensability among the sub-indices is belowaverage. As the variability among pillars for a given country (i.e. the disposition of pillars to improve or deteriorate the final ranking) changes over time, the rate at which the better values can reduce the worse values is also changing. The 4th and 7 th columns of the table comply with this fact and show the GCR editions ranked according to expected compensability from the highest to the lowest.

Another essential aspect of variability is linked to the differences among countries in a particular pillar (see Table 5). In the case of more significant variability of the countries' results (in a given pillar), the impact of the favourable country's value (i.e. outstanding or at least above-average value) on the country's final position is more significant compared to the impact of a similar favourable country's value in a pillar with lower variability. Table 5 shows the average variability inside pillars (i.e. among countries in individual pillars). The pillar's ranking in the 3rd and 5th columns enables (in combination with the pillar's weights described in Table 3) evaluation of the importance of positive value in this pillar for the country's final position.

Table 5 shows that the 2nd pillar - infrastructure, followed by the 10th pillar market size and 9th pillar - technological readiness had the highest importance for country's ranking in the GCR 2007-17. The smallest variability among countries in the 7 th pillar - labour market efficiency (and subsequently in the 6th and 11th pillars) indicates that an excellent (or above-average) performance in these aspects of global competitiveness has lower importance for the country's overall ranking. Table 5 also shows that the excellent performance (competitive advantage) of a country in sub-index A has slightly higher importance for the country's ranking compared to other subindices. This conclusion - in combination with the WEF's weighting scheme - is relevant especially for developing countries (in the 1st stage of development).

The following Figures 1-3 use results based on the WEF's data from the GCR editions 2007-17 and show the position of Japan, South Korea and Vietnam according to the $\mathrm{GCl}, \mathrm{AGCl} 3, \mathrm{AGCl} 12, \mathrm{GAGCl} 3$ and GAGCl12. Using arithmetic mean, Tables 6-8 enable us to identify the main competitive advantages and disadvantages of countries in the GCR edition 2007-17 (column named GCl rank/value) and in the GCR edition 2017-19 (column named GCl 4.0 rank/value). Competitive advantages and disadvantages are usually identified by the country's rank in the given indicator or pillar. With this in mind, a country in a given pillar (indicator) can achieve a relatively good position even with a lower value and vice versa (i.e. a worse position with a higher indicator value). Since our goal is to assess the impact of compensability on the country's performance, the competitive pros and cons are evaluated according to the pillar's values. 
Table 5. Variability inside pillars/sub-indices and the average value in pillars/sub-indices (the GCR 2007-17)*

\begin{tabular}{|c|c|c|c|c|c|c|c|}
\hline Pillar & s.d. & Rank & $\begin{array}{l}\text { Arithmetic } \\
\text { mean }\end{array}$ & Rank & Sub-index & s.d. & $\begin{array}{c}\text { Arithmetic } \\
\text { mean }\end{array}$ \\
\hline 1st pillar: Institutions & 0.904 & 5. & 4.14 & 8. & \multirow{4}{*}{$\begin{array}{l}\text { A. Basic } \\
\text { requirements }\end{array}$} & \multirow{4}{*}{0.814} & \multirow{4}{*}{4.65} \\
\hline 2nd pillar: Infrastructure & 1.220 & 1. & 4.13 & 9. & & & \\
\hline $\begin{array}{l}\text { 3rd pillar: Macro- } \\
\text { economic environment }\end{array}$ & 0.884 & 6. & 4.82 & 2. & & & \\
\hline $\begin{array}{l}\text { 4th pillar: Health and } \\
\text { primary education }\end{array}$ & 0.877 & 8. & 5.41 & 1. & & & \\
\hline $\begin{array}{l}\text { 5th pillar: Higher } \\
\text { education and training }\end{array}$ & 0.980 & 4. & 4.28 & 5. & \multirow{6}{*}{$\begin{array}{l}\text { B. Efficiency } \\
\text { enhancers }\end{array}$} & \multirow{6}{*}{0.695} & \multirow{6}{*}{4.21} \\
\hline $\begin{array}{l}\text { 6th pillar: Goods market } \\
\text { efficiency }\end{array}$ & 0.573 & 11. & 4.38 & 3. & & & \\
\hline $\begin{array}{l}\text { 7th pillar: Labour market } \\
\text { efficiency }\end{array}$ & 0.559 & 12. & 4.35 & 4. & & & \\
\hline $\begin{array}{l}\text { 8th pillar: Financial } \\
\text { market development }\end{array}$ & 0.747 & 9. & 4.22 & 6. & & & \\
\hline $\begin{array}{l}\text { 9th pillar: Technological } \\
\text { readiness }\end{array}$ & 1.125 & 3. & 4.09 & 10. & & & \\
\hline 10th pillar: Market size & 1.146 & 2. & 3.97 & 11. & & & \\
\hline $\begin{array}{l}\text { 11th pillar: Business } \\
\text { sophistication }\end{array}$ & 0.737 & 10. & 4.18 & 7. & \multirow{2}{*}{$\begin{array}{l}\text { C. Innovation } \\
\text { and soph. } \\
\text { factors }\end{array}$} & \multirow[t]{2}{*}{0.793} & \multirow[t]{2}{*}{3.87} \\
\hline 12th pillar: Innovation & 0.878 & 7. & 3.55 & 12. & & & \\
\hline $\begin{array}{l}\text { Mean (of the pillar's } \\
\text { values) }\end{array}$ & 0.886 & & 4.29 & & & & \\
\hline $\begin{array}{l}\text { Median (of the pillar's } \\
\text { values) }\end{array}$ & 0.881 & & 4.20 & & & & \\
\hline
\end{tabular}

Note: * In this table, the arithmetic means for the reference period (i.e. the arithmetic mean of standard deviations (s.d.) founded in individual years and the arithmetic mean of pillar's values measured in individual years) are presented.

Source: Own computation based on the WEF methodology, WEF (2017a, b).

The different weights used in the different attitudes to a linear aggregation (see relevant columns in Tables 6-8) in combination with the abovementioned aspects of variability (the country's predisposition to compensability on the level of pillars and subindices, the pillar's disposition to affect the country's rank) are the key factors for the explanation of the ascertained results.

\subsection{Japanese Competitiveness}

According to the GCR editions, Japan is a big developed economy with excellent results in the innovation and sophistication factors. However, the macroeconomic environment continues to undermine Japan's competitiveness performance, although the situation 
has improved over the past years (thanks to a lower, yet still huge, budget deficit). This improvement is a result of better government budget balance and higher gross national savings. Japan is also beset by the rigidities and lack of dynamics of its labour market. The domestic market is relatively uncompetitive and closed, with high barriers to entry and business creation.

The country's overall performance is primarily driven by productive innovation ecosystem, market size, high-quality physical and digital infrastructure, and a healthy and educated workforce. Japanese firms are highly sophisticated (they employ unique products and production processes and have significant control over international distribution). High-quality research institutions, company spending on R\&D and high availability of scientists and engineers contribute to the country's overall highly innovative environment. Overall, the Japanese innovation process has a positive influence on Japanese ranking despite the small decrease in the ranking (consistently ranked in the top 5 between 2007 and 2015, Japan lost three positions in GCR 2016-17 while its position in GCR 2017-18 was 6th place).

All methods used - i.e. comparison of the weighting schemes, identification of strengths and weaknesses (see Table 6), and graphical presentation of changes in national competitiveness (see Figure 1) - can help to explain the differences among our results. Due to the WEF's original weighting scheme, Japan's competitive advantages can compensate for the negative influence of worse outcomes in the 3rd, 5th and 8th

Table 6. Strengths and weaknesses of Japanese competitiveness (sample: 114 countries, ranks according to average values in pillars - GCl: 2007-2017 and GCl 4.0: 2017-2019)

\begin{tabular}{|c|c|c|c|c|c|c|}
\hline & \multicolumn{6}{|c|}{ Strengths } \\
\hline \multirow{2}{*}{\multicolumn{2}{|c|}{ GCI (rank/value) }} & \multicolumn{3}{|c|}{ Weights } & \multirow{2}{*}{\multicolumn{2}{|c|}{ GCl 4.0 (rank/value) }} \\
\hline & & \multirow{2}{*}{$\begin{array}{r}\mathrm{GCl} \\
5\end{array}$} & \multirow{2}{*}{$\begin{array}{c}\mathrm{AGCl} 3 \\
8.33\end{array}$} & \multirow{2}{*}{$\begin{array}{c}\mathrm{AGCl} 12 \\
\mathrm{GCl} 4.0 \\
8.33\end{array}$} & & \\
\hline $\begin{array}{l}\text { 4. Health and primary } \\
\text { education }\end{array}$ & 9. (6.4) & & & & 5. Health & 3. $(100)$ \\
\hline 10. Market size & 4. $(6.1)$ & 8.5 & 5.56 & 8.33 & 4. Macro stability & 42. (94.4) \\
\hline \multirow[t]{2}{*}{ 2. Infrastructure } & 8. $(6.0)$ & 5 & 8.33 & 8.33 & 2. Infrastructure & 5. $(92.2)$ \\
\hline & \multicolumn{6}{|c|}{ Weaknesses } \\
\hline \multirow{2}{*}{\multicolumn{2}{|c|}{ GCI (rank/value) }} & \multicolumn{3}{|c|}{ Weights } & \multirow{2}{*}{\multicolumn{2}{|c|}{$\mathrm{GCl} 4.0$ (rank/value) }} \\
\hline & & $\mathrm{GCl}$ & $\mathrm{AGCl} 3$ & $\begin{array}{l}\text { AGCl12 } \\
\text { GCl } 4.0\end{array}$ & & \\
\hline 3. Macro environment & 98. (4.0) & 5 & 8.33 & 8.33 & 8. Labour market & 18. (70.8) \\
\hline $\begin{array}{l}\text { 8. Financial market } \\
\text { development }\end{array}$ & 25. (4.8) & 8.5 & 5.56 & 8.33 & 1. Institutions & 20. (70.1) \\
\hline $\begin{array}{l}\text { 7. Labour market } \\
\text { efficiency }\end{array}$ & 14. (4.9) & 8.5 & 5.56 & 8.33 & 7. Product market & 6. (71.3) \\
\hline
\end{tabular}

Source: Author's calculation and processing based on the WEF methodology, WEF (2017a, b; 2019a, b). 


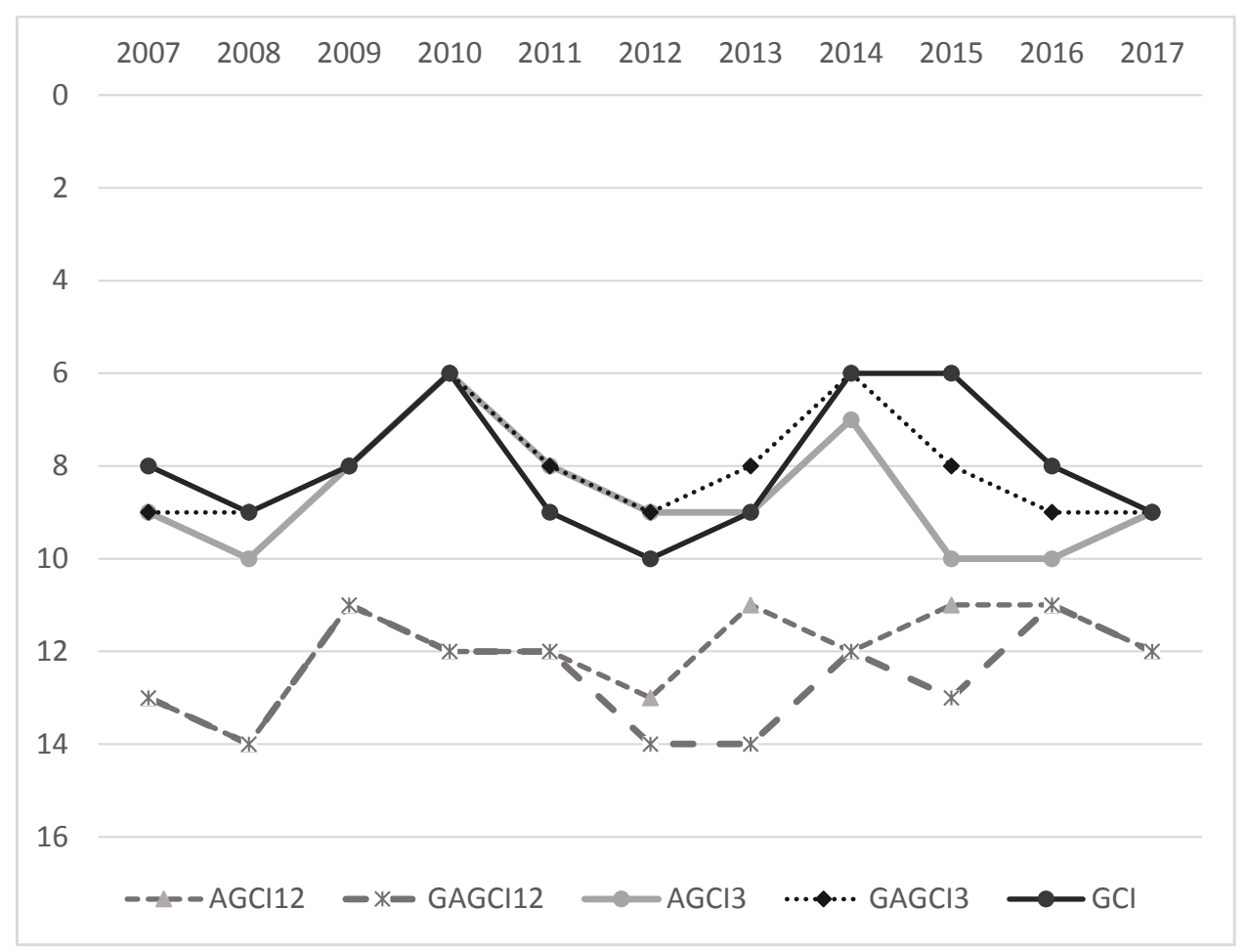

Figure 1. Changes in the national competitiveness of Japan - comparison of different attitudes to the final aggregation

Source: Own calculation and processing based on the WEF methodology, WEF (2017a, b).

pillars (due to their weights, these pillars have lower importance for the final rank). Therefore, the weighting schemes which allow the compensability among the pillars (e.g. weighting schemes based on the arithmetic mean - $\mathrm{GCl}, \mathrm{AGCl} 3$ and $\mathrm{AGCl} 12$ ) have a positive influence on the Japanese position. Table 9 shows a more detailed view of countries' results.

Japan - except for results in GCR 2011, 2012 and 2013 - achieved the best ranking when the original WEF methodology is applied. The highest average value of the final indicator was found using the same weights of sub-indices ( $\mathrm{AGCl} 3)$. The results shown in Figure 1 can be explained mainly by: 1) the below-average variability among the sub-indices, 2) Japanese excellent results in the pillars of innovative subindex (2nd place in the 11th pillar and 4th place in the 12th pillar), 3) the highest weights in the $\mathrm{GCl}$ and $\mathrm{AGCl} 3$ methodology. Due to the lowest weight for sub-index A (basic requirements) in the WEF's weighting scheme, compensation of competitive disadvantages connected with this sub-index is relatively easy. The abovementioned Japanese macroeconomic instability (visible in the 3rd pillar), which has an average effect on the overall ranking, is offset by the country's excellent performance in the 2nd and 4th pillar. (In addition, the 2 nd pillar has the highest potential to influence the ranking due to the highest variability among countries.) The impact of the competitive 
disadvantages in the 7th and 8th pillars is reduced both by the above-average values in these pillars and by their relatively low influence on the ranking. The exceptionally worse Japanese ranking according to the $\mathrm{GCl}$ methodology (compared to the AGCI3 and the GAGCl3) in the years 2011, 2012 and 2013 can be explained especially by the differences in the weighting schemes. The system of weights in the AGCI3 attributes the least importance to the pillars with a competitive disadvantage in sub-index $B$ (the 7 th and 8th pillars) and in sub-index A. Simultaneously, the AGCl3 allows for compensating competitive weakness in the 3 rd pillar for positive results in the 2 nd and 4 th pillars. It is necessary to take into account that our findings also reflect a changing disposition to compensability among pillars (the highest in 2015, 2014 and 2012) and sub-indices (the highest in 2011, 2010 and 2009).

\subsection{Korean Competitiveness}

According to the GCR 2007-17, South Korea's overall position in the ranking was stable in the last five years. Compared to other developed economies, the country presented significant disparities among pillars. South Korea's improvement was largely driven by its remarkable infrastructure and a highly favourable macroeconomic environment. Areas in which South Korea consistently underperforms are institutions, labour market efficiency (63rd place in the period 2007-17 due to the evaluation of labour market

Table 7. Strengths and weaknesses of South Korea's competitiveness (sample: 114 countries, ranks according to average values in pillars - GCl: 2007-2017 and GCl 4.0: 2017-2019)

\begin{tabular}{|c|c|c|c|c|c|c|}
\hline & \multicolumn{6}{|c|}{ Strengths } \\
\hline \multirow{2}{*}{\multicolumn{2}{|c|}{ GCI (rank/value) }} & \multicolumn{3}{|c|}{ Weights } & \multirow{2}{*}{\multicolumn{2}{|c|}{ GCl 4.0 (rank/value) }} \\
\hline & & \multirow{2}{*}{$\begin{array}{r}\mathrm{GCl} \\
5\end{array}$} & \multirow{2}{*}{$\begin{array}{c}\mathrm{AGCl} 3 \\
8.33\end{array}$} & \multirow{2}{*}{$\begin{array}{c}\mathrm{AGCl} 12 \\
\mathrm{GCl} 4.0 \\
8.33\end{array}$} & & \\
\hline $\begin{array}{l}\text { 4. Health and primary } \\
\text { education }\end{array}$ & 23. (6.3) & & & & 4. Macro stability & 11. (100) \\
\hline 3. Macro environment & 3. (6.3) & 5 & 8.33 & 8.33 & 5. Health & 12. $(97.0)$ \\
\hline \multirow[t]{3}{*}{ 2. Infrastructure } & 12. $(5.8)$ & 5 & 8.33 & 8.33 & 2. Infrastructure & 6. (91.3) \\
\hline & \multicolumn{6}{|c|}{ Weaknesses } \\
\hline & & \multicolumn{3}{|c|}{ Weights } & \multirow{2}{*}{\multicolumn{2}{|c|}{ GCl 4.0 (rank/value) }} \\
\hline \multicolumn{2}{|l|}{ GCl (rank/value) } & $\mathrm{GCl}$ & $\mathrm{AGCl} 3$ & $\begin{array}{l}\mathrm{AGCl} 12 \\
\mathrm{GCl} 4.0\end{array}$ & & \\
\hline $\begin{array}{l}\text { 8. Financial market } \\
\text { development }\end{array}$ & 64. (4.1) & 8.5 & 5.56 & 8.33 & 7. Product market & 59. $(56.0)$ \\
\hline 1. Institutions & 47. (4.1) & 5 & 8.33 & 8.33 & 8. Labour market & 47. (62.3) \\
\hline $\begin{array}{l}\text { 7. Labour market } \\
\text { efficiency }\end{array}$ & 63. (4.3) & 5 & 5.56 & 8.33 & 1. Institutions & 27. (64.9) \\
\hline
\end{tabular}

Source: Author's processing based on the WEF methodology, WEF (2017a, b; 2019a, b). 


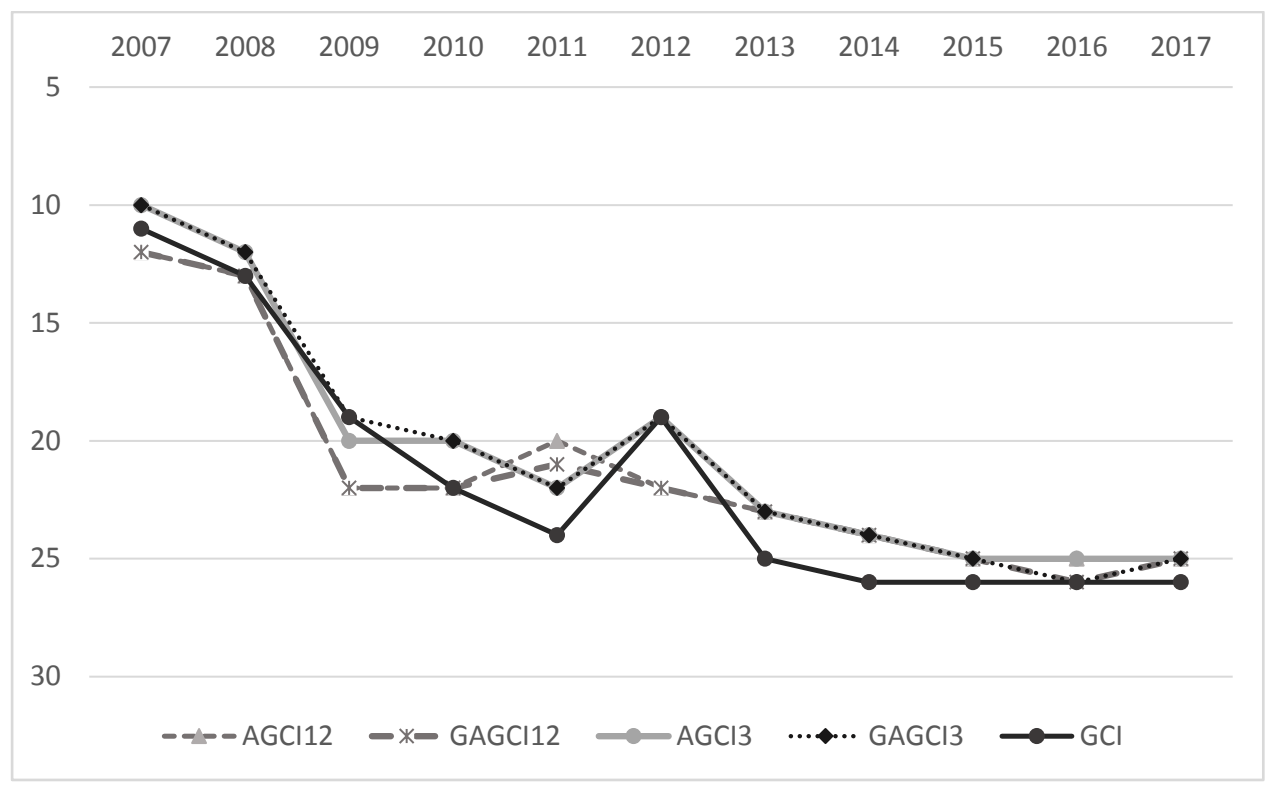

Figure 2. Changes in the national competitiveness of South Korea - comparison of different attitudes to the final aggregation

Source: Author's calculation and processing based on the WEF methodology, WEF (2017a, b).

flexibility - South Korea's position is caused notably by the conflictual labour-employer relations and high redundancy costs), credit access conditions, and low confidence in the banking system. The GCR official commentary focuses on the trend over the last decade. Looking back at South Korea's performance, it is one of the few advanced economies to have experienced a general decline in performance for a majority of pillars. However, the last GCR editions indicate stabilisation and positive signals.

Taking into account the WEF's and alternative weighting schemes, competitive advantages and disadvantages, predisposition to compensability among pillars and sub-indices, and the results presented in Figure 2, we can summarise that the WEF methodology worsens South Korea's results compared to other aggregation methods. The AGCI3 methodology brings the highest average value during the period 2007-2017. Both lower weights and lower values in South Korea's competitive advantages explain why South Korea has smaller rate of compensability than Japan.

Unlike Japan and Vietnam, application of the WEF's weighting scheme brings South Korea the worst results (except for 2009 and 2012). South Korea - in comparison with Japan and Vietnam - evinces the most significant predisposition to compensability of the pillars and, simultaneously, only slightly below-average variability among subindices. The competitive advantages (due to the above average values) lie in the pillars with the highest (2nd pillar), the above-average (10th pillar), and the average (3rd and 12th pillars) influence on South Korea's ranking. South Korea, as well as Japan, has a competitive disadvantage in the pillars with the lowest (7th pillar) and average (8th pillar) variability; i.e. in the pillars with a relatively small impact on the country's 
ranking. Unlike Japan, stronger disadvantages (due to slightly below-average values) of South Korea were identified in those pillars. The exception in South Korean results, the best rank in 2011 (according to the AGCl12 methodology), is caused by: 1) South Korean improvements in the $2 \mathrm{nd}, 3 \mathrm{rd}$ and 4th pillars, 2) the higher weights of these pillars, and 3) predisposition of pillars to affect overall ranking. South Korea's relative deterioration (i.e. deterioration in the WEF ranking - see Dataset WEF) in sub-indices $B$ and $C$ supported by the weights of these sub-indices in the $\mathrm{GCl}$ and the $\mathrm{AGCl} 3$ can explain the opposite trend, i.e. worse ranking, in these composite indicators contrary to the positive trend, i.e. better ranking, in the AGCI12 and the GAGCl12. The changing potential for substitution among the pillars (the highest tendency to compensability was identified in 2015, 2014 and 2017) and sub-indices (the highest tendency in 2017, 2016 and 2015) has also contributed to the differences among ascertained results.

\subsection{Vietnamese Competitiveness}

Vietnamese competitiveness is significantly driven by its market size. Significant improvements are necessary across all pillars, notably among the basic requirement factors and higher education, as firms perceive that the lack of an educated workforce constitutes a significant barrier for doing business. The country's position in the 5th pillar (higher education training) is negatively influenced by the perceived low quality of business schools and local (un)availability of specialised training services. Availability of latest technologies for Vietnamese firms is limited and deteriorates the country's rank in the 9 th pillar (technological readiness).

Table 8. Strengths and weaknesses of Vietnamese competitiveness (sample: 114 countries, ranks according to average values in pillars - GCl: 2007-2017 and GCI 4.0: 2017-2019)

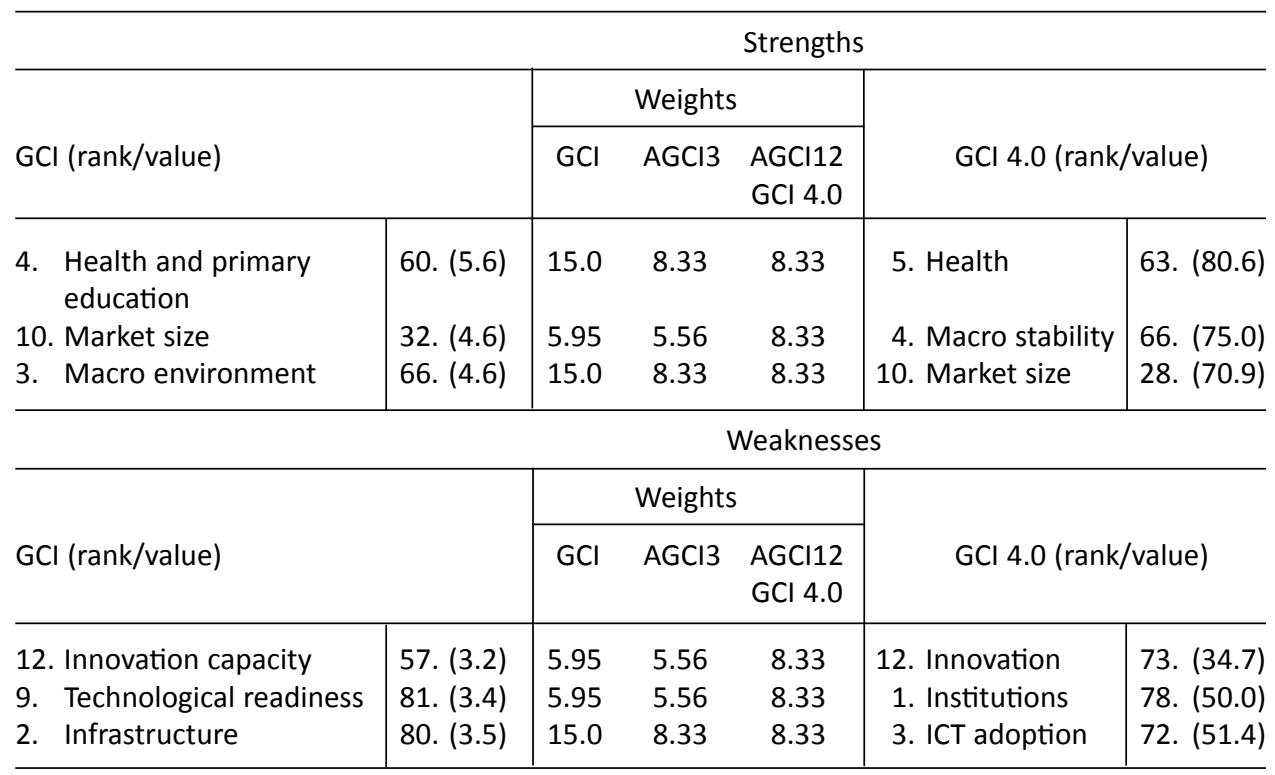

Source: Own processing based on the WEF methodology, WEF (2017a, b; 2019a, b). 


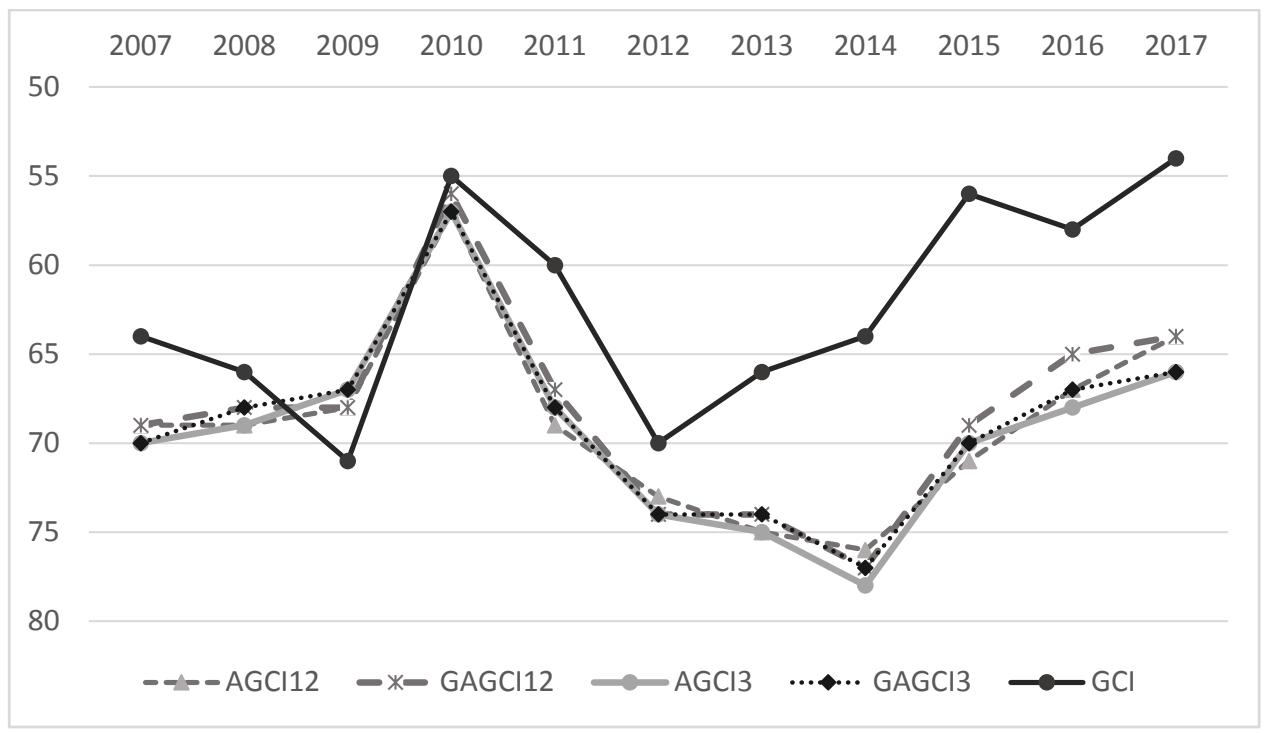

Figure 3. Changes in the national competitiveness of Vietnam - comparison of different attitudes to the final aggregation

Source: Own calculation and processing based on the WEF methodology, WEF $(2017 a, b)$.

Due to the low local supplier quality and quantity, value chain breadth and extent of marketing, the pillar of business sophistication is a persisting weakness of the Vietnamese economy. Innovative performance is negatively influenced by the quality of scientific research institutions and the low number of Patent Cooperation Treaty (PCT) patents.

The results achieved for Vietnam (see Table 8 and Figure 3) proved that using the WEF's weighting scheme is the best choice for this country. The competitive weaknesses residing in the 11th and 12th pillars play a crucial negative role in the Vietnamese ranking, especially when the alternative attitudes to the $\mathrm{GCl}$ were used. Since the pillars with competitive advantages and disadvantages have different weights, the positive results manifest sufficient compensating power in the $\mathrm{GCl}$ methodology. The pillars with the lowest values have a relatively low influence on the $\mathrm{GCl}$ value - the nominal weights of the 11 th and 12 th pillars are only $2.5 \%$ (but $16.67 \%$ in the AGCI3 and $8.33 \%$ in the $\mathrm{AGCl} 12$ ).

The best position according to the $\mathrm{GCl}$ can be explained namely by: 1) the slightly above-average variability among sub-indices, 2 ) the biggest emphasis put on the subindex of basic requirements $(60 \%), 3$ ) the competitive advantages in the pillars of subindex A, and 4) the lowest weights of the innovative sub-index C (5\%). Only in the 2009 $\mathrm{GCl}$ rating is Vietnam penalised by the WEF weighting scheme with the worst result compared to the alternatives. The reasons are the following: 1) the negative change in the 3 rd pillar, i.e. a fall of more than 40 places in macroeconomic performance, and 2) the deterioration in the infrastructure pillar (a significantly lower value compared to the previous year). The other argument lies in the lowest predisposition to compensability 
of the pillars and the sub-indices in this year (2009). The lowest value and the worst Vietnamese rank in the $\mathrm{AGCl} 3$ is explained especially by the weighting scheme - the AGCl3 attaches the highest weight (16.67\%) to the innovative pillars. The changing potential for substitution among the pillars (the highest tendency to compensability was identified in 2007, 2014 and 2015) and sub-indices (the highest tendency in 2015, 2014 and 2017) has also contributed to the differences among obtained results.

Table 9 summarises the results of our analysis from the following points of view: (a) comparing the country's ranks according to the different composite indicators in the period 2007-2017; (b) comparing the WEF's results according to the original (the $\mathrm{GCl}$ ) and the new methodology (the GCl 4.0) in the period 2017-19; (c) seeking the composite indicator with the best average value for the country (see the values written in bold); and (d) comparing our three chosen countries according to the variability among the $\mathrm{Cls}$ (see the column s.d.*).

Table 9. Countries' results in the different composite indicators (2017)

\begin{tabular}{lcrrrrrr}
\hline \multirow{2}{*}{ Country/Cl } & \multicolumn{7}{c}{$\mathrm{GCl}(2007-2017) / G C l 4.0(2017-19)$} \\
\cline { 2 - 8 } & AGCl12 & GAGCl12 & AGCl3 & GAGCl3 & GCl & GCl 4.0 & s.d.* \\
\hline \multirow{2}{*}{ Vietnam } & 4.05 & 4.00 & 3.96 & 3.95 & 4.20 & 59.18 & \\
& 72. & 70. & 72. & 70. & 62. & 72. & 0.091 \\
Japan & 5.39 & 5.35 & 5.46 & 5.45 & 5.42 & 82.1 & \\
South Korea & 13. & 13. & 10. & 9. & 8. & 7. & 0.04 \\
& 5.16 & 5.11 & 5.16 & 5.15 & 5.07 & 78.8 & \\
& 22. & 22. & 20. & 20. & 21. & 14. & 0.036 \\
\hline
\end{tabular}

Note: s.d.* the standard deviation among the composite indicators in period 2007-17 (the average of s.d. in individual years).

Source: Author's computation based on the WEF methodology, WEF (2017a, b; 2019a, b).

A comparison of $\mathrm{GCl}$ and $\mathrm{GCl} 4.0$ results indicated that the new methodology (especially the weighting system based on the same weights for all pillars) rewards countries with balanced performance in the pillars (South Korea) and penalises countries with a competitive disadvantage in the innovation ecosystem (Vietnam).

\section{Conclusion}

Being inspired by the new WEF methodology (the $\mathrm{GCl} 4.0$ ) and by the critical comments to the original WEF methodology (the $\mathrm{GCl}$ ), adjusted weighting schemes (the AGCl3, $A G C I 12, G A G C l 3, G A G C l 12$ ) were used with the aim to offer the relevant alternative to the original weighting scheme applied by the WEF (different weights of the subindices and pillars for different groups of countries divided according to their stages of development). Our alternatives to the WEF's weighting scheme are based on the same weights being applied to all countries. In this point of view, our alternatives to the $\mathrm{GCl}$ prove to be fairer (unbiased) and are able to decrease the distortions caused by the economic, social and cultural differences among countries (the so-called national 
bias). A comparison of countries' results allowed us to identify which attitude to the final aggregation improves or worsens the individual countries rank. Our main finding is that the weighting scheme, the variability among pillars and sub-indices for the given country (measured by the standard deviation of pillars), and the predisposition of pillars to affect the countries' ranking (measured by the variability among the countries in the given pillars) have an essential impact on the countries' ranking. The original WEF's weighting scheme has a positive impact on the evaluation of the big countries (the results in the 10th pillar were identified as the competitive advantage for all our countries). This weighting scheme also rewards good results of the developed countries in the 3rd sub-index (innovation and sophisticated factors), while it does not significantly penalise the developing countries' gaps in the same sub-index (see above, e.g. the nominal weight of the 11th and 12th pillars for Vietnam).

If a country is positively evaluated in the pillars with high importance for the overall ranking (the pillars with high value, high predisposition to affect the ranking and high weight according to the original WEF methodology) and manifests strong tendency to compensability, the linear aggregation will enable the compensation of the negative results assigned in the pillars with smaller weights. The reasons for the differences among the $\mathrm{GCl}$ and the modified composite indices in the case of Japan are that Japanese weaknesses (see Table 6 and our commentary above) are grounded in the pillars with relatively low impact on the ranking, while Japanese strengths consists in the sub-index of innovation factors, which has the highest WEF weights for developed countries and a relatively strong potential for substitution for countries with excellent performance.

Comparison of South Korea's results according to the WEF's weighting scheme and our alternative attitudes shows that the same weights for all pillars (the AGCI12) and sub-indices (the $A G C I 3$ ) represent a better choice for South Korea than the WEF's weighting scheme. The reasons are: 1) South Korea's strengths (the 4th, 3rd and 2nd pillar) are grounded in the pillars with low WEF weights and therefore with lower impact on the overall ranking; 2) simultaneously, their relatively strong predisposition to affect South Korea's rank is weakened by important characteristics of South Korea's weaknesses (the 7th and 8th pillar), which lean on the sub-index of efficiency enhancers with high WEF weight for countries in the innovation-driven stage of development (therefore, these competitive indicators have more negative impact on the country's rank, e.g. compared to Vietnam).

Using the WEF's weighting scheme is the best choice for Vietnamese ranking. This fact is primarily caused by the WEF's weighting scheme which rewards competitive advantages in sub-index $A$ (basic requirements) and does not penalise competitive weaknesses in the innovative sub-index so strongly. The above-average Vietnamese predisposition to compensability among sub-indices is projected into our findings as well as the WEF's weighting scheme.

Our comparison between the original and new WEF methodology indicates that the new methodology (based on smaller representation of soft data and the same weights of pillars) reduces the distortions caused by the so-called national bias and appreciates the higher values across all pillars of competitiveness in the developed countries (see the changes in ranking - the improvement of Korea and the deterioration of Vietnam). 


\section{References}

Berger, T., \& Bristow, G. (2009). Competitiveness and the benchmarking of nations - A critical reflection. International Atlantic Economic Society, 15(4), 378-392. https://doi.org/10.1007/ s11294-009-9231-x

Browne, C., Di Battista, A., Geiger, T., \& Verin, S. (2016). The executive opinion survey: The voice of the business community. In K. Schwab (Ed.), The Global Competitiveness Report 20162017 (pp. 77-87). Geneva, Switzerland: World Economic Forum.

Cho, D.S., \& Moon, H.C. (2013). International review of national competitiveness: A detailed analysis of sources and rankings. Cheltenham, UK: Edward Elgar Publishing Limited.

Freudenberg, M. (2003). Composite indicators of country performance: A critical assessment (OECD Science, Technology and Industry Working Paper, No. 2003/16). Paris, France: Organisation for Economic Co-operation and Development. https://doi.org/10.1787/ 405566708255

Hudrlikova, L. (2013). Composite indicators as a useful tool for international comparison: The Europe 2020 example. Prague Economic Papers, 22(4), 459-473. https://doi.org/10.18267/j. pep.462

Necadova, M. (2015). Selected approaches to measurement of national competitiveness and the results of Visegrad Group in years 2007-2014. Acta Oeconomica Pragensia, 23(2), 22-39. https://doi.org/10.18267/j.aop.468

Necadova, M. (2019). Changes in economic sentiment indicators before and after economic crisis (Position of Visegrad Group and Germany in EU). Central European Business Review, 8(4), 5585. https://doi.org/10.18267/j.cebr.220

Necadova, M., \& Soukup, J. (2013). The Controversial concept of national competitiveness and the results of the Visegrad Group in international rankings of competitiveness (2007-2012). Politická ekonomie, 61(5), 583-604.

OECD/EU/JRC. (2008). Handbook on constructing composite indicators: Methodology and user guide. Paris, France: OECD Publishing.

Ochel, W., \& Röehn, O. (2006). Ranking of countries - the WEF, IMD Fraser and heritage indices. CESifo DICE Report, 4(2), 48-60.

Pérez-Moreno, S., Rodríguez B., \& Luque, M. (2016). Assessing global competitiveness under multicriteria perspective. Economic Modelling, 53 (February), 398-408. https://doi.org/ 10.1016/j.econmod.2015.10.030

Saisana, M., Saltelli, A., \& Tarantola, S. (2005). Uncertainty and sensitivity analysis techniques as tools for the quality assessment of composite indicators. Journal of the Royal Statistical Society, 168, 307-323.

WEF (2010). The Global Competitiveness Report 2010-11. Geneva, Switzerland: Author. Retrieved from http://www3.weforum.org/docs/WEF_GlobalCompetitivenessReport_2010-11.pdf

WEF (2017a). GCI Dataset. Geneva, Switzerland: Author. Retrieved from http://reports.weforum. org/global-competitiveness-index-2017-2018/downloads/

WEF (2017b). The Global Competitiveness Report 2017-2018. Geneva, Switzerland: Author. Retrieved from http://www3.weforum.org/docs/GCR2017-2018/05FullReport/TheGlobal CompetitivenessReport2017\%E2\%80\%932018.pdf

WEF (2019a). GCl 4.0 Dataset. Geneva, Switzerland: Author. Retrieved from http://reports. weforum.org/global-competitiveness-report-2019/downloads/

WEF (2019b). The Global Competitiveness Report 2019. Geneva, Switzerland: Author. Retrieved from http://www3.weforum.org/docs/WEF_TheGlobalCompetitivenessReport2019.pdf 